\title{
A Questão Agrária e a Transformação Rural Neoliberal na América Latina*
}

Recebido: 25-09-2018

Aprovado: 06-10-2018

Cristóbal Kay ${ }^{1}$

$\mathrm{O}$ artigo começa por lembrar seus leitores do período de reforma agrária de meio século atrás, montando o cenário para discutir as grandes transformações engendradas pelo neoliberalismo na era da globalização. Em sequência, analisa o controle em aumento do capital corporativo nacional e transnacional sobre a economia e a sociedade rurais por meio dos imperativos do mercado que fomentaram processos de concentração, assim como a remoção e o redução do poder dos camponeses e da força de trabalho rural. Segue-se a investida ao contra-movimentos que empregam seus esforços em prol dos direitos indígenas, a justiça ambiental, a 'soberania alimentar', a agroecologia e um sistema mundo agrário alternativo. Essas transformações e contra-movimentos revelam temas emergentes e encorajam, ou mesmo demandam, a busca por abordagens inovadores em relação à questão agrária. Enquanto há meio século a questão agrária se centrava na alta concentração fundiária, argumento que hoje a mesma gira em torno da concentração do capital e da dominação do agronegócio. Neste curto artigo, posso apenas fornecer uma visão geral das transformações no campo e realçar algumas das principais tendências desde a virada neoliberal na América Latina. Essas transformações apresentam especificidades em cada país, como atesta-se nos estudos de dezessete países compilados nos estudo enorme de três volumes editado por Almeyra et al. (2014).

\section{Da Reforma Agrária à Reconcentração Fundiária}

Nas décadas de 1960 e 1970, a questão agrária chave se centrava em torno do sistema de posse da terra altamente desigual e das condições laborais de exploração tipo 'feudal' em

\footnotetext{
* Tradução do original em inglês para o português por Rafael Moreira de Mello.

${ }^{1}$ Professor emérito do Instituto Internacional de Estudos Sociais, Haia, Erasmus University Rotterdam. Contato: kay@iss.nl
} 
grandes propriedades fundiárias. Movimentos camponeses e partidos políticos de esquerda, assim como alguns partidos do centro, pressionaram crescentemente pela implementação de reformas agrárias. Durante a década de 1960 até o começo dos anos 1980, uma onda de reformas agrárias foram implementadas em vários países, com variação na intensidade e no resultado (Kay, 1998). A crise da dívida e os programas de ajuste estrutural concomitantes da década de 1980, que trouxeram a era neoliberal após meio século de desenvolvimentismo estatal e industrialização por substituição de importações, tiveram consequências profundas para a economia e sociedade rurais.

O conjunto de políticas de liberalização dos mercados da terra, do trabalho e de capitais, assim como a abertura das economias aos mercados mundiais e a multiplicação de acordos de livre comércio, levaram ao boom da exportação de commodities. Dada a alta na rentabilidade do investimento no setor agroexportador, os fazendeiros capitalistas mudaram sua produção, de 'safras tradicionais' como trigo e milho à exportação agrícola não tradicional, como soja, frutas e horticultura. Isso, por sua vez, alimentou um novo processo de concentração fundiária e, em alguns casos, "apropriação de terras" e preocupações acerca da "internacionalização" da agricultura. Em vários casos, a concentração de terras chegou a níveis similares ao período anterior à Reforma Agrária, vide os casos do Chile, do Equador e do Peru (Kay, 2014, p. 27). Ao passo que alguns senhorios conseguiram completar a transição para agricultura capitalista competitiva de pleno direito, a mudança para as exportações não tradicionais foi principalmente conduzida por novos empreendedores capitalistas oriundos de, ou ligados a, setores da mineração, da indústria, do comércio e das finanças, e, às vezes, associados a investidores estrangeiros (Borras et al., 2012). Pode-se argumentar que, de modo irônico, foi o processo de reforma agrária que facilitou posteriormente o processo de concentração fundiária e de capitais, uma vez que enfraqueceu o controle das classes proprietárias tradicionais, facilitando, com isso, o desenvolvimento posterior de um mercado ativo de terras com a virada neoliberal.

\section{A Dominação do Capital Financeiro e a Agricultura}

O capital conglomerado começou a controlar os setores mais rentáveis da agricultura. A terra cultivada com soja multiplicou-se por quase 40 desde 1970 e se tornou a safra dominante na exportação. A área cultivada com cana-de-açúcar e óleo de palma também cresceu substancialmente. Conhecidos como "safras flex" por terem múltiplos usos (alimento, ração animal, agro ou biocombustíveis), constituem o "complexo alimento-raçãocombustível" e são, portanto, especialmente atraentes para investidores e especuladores 
capitalistas, uma vez que o destino final da safra depende dos preços prevalecentes (Borras et al., 2012). A demanda mundial por madeira e polpa para a fabricação de papel aumentou o desmatamento da Amazônia, expandindo em grande escala as plantações florestais. Uma parcela desta expansão na área cultivada e florestal avançou sobre terras pertencentes, por meio de direitos consuetudinários ou títulos legais, a comunidades indígenas ou camponesas e agricultores familiares. Realizado por meio da força e meios involuntários ou compras duvidosas, caracteriza-se enquanto "usurpação de terras". Embora a usurpação de terras não tenha alcançado as dimensões observadas na África e na Ásia, tem-se tornado um problema crescente para comunidades e pequenos proprietários na América Latina.

Outra característica deste novo capital corporativo encontra-se na participação substancial de capital oriundo de outros países latino-americanos, conhecido por alguns como capital 'translatino' (Borras et al., 2012). O Paraguai apresenta um caso extremo, em que aproximadamente dois terços das terras cultivadas com soja pertencem, majoritariamente, a capitais brasileiros (conhecidos como 'brasiguayos') e argentinos. De modo similar, fazendeiros brasileiros detêm uma presença substantiva no cultivo da soja na Bolívia oriental, e no Uruguai essa presença predominante é marcada pelo capital argentino. Estes capitais corporativos 'translatinos' não se limitam a um país, no geral a um vizinho, mas se estendem para além do mesmo.

Além do mais, os capitalistas argentinos são pioneiros dos "pools of siembra", um sistema de gerenciamento de fazendas que experimentaram em seu próprio país antes de o utilizarem em seus investimentos no Uruguai e no Paraguai. Utilizam agricultura intensiva, sementes transgênicas, agroquímicos e técnicas de plantio direto. Os mesmos manejam milhares, dezenas de milhares e até centenas de milhares de hectares de terra, uma parcela da qual é de sua propriedade e outra, arrendada, distribuídas por diversas áreas do país afora, assim diminuindo o risco. Os donos destes agronegócios conseguem assegurar grandes quantidades de capital para os seus investimentos devido a seus laços estreitos com o capital financeiro e os fundos de investimento internacionais. Contratam profissionais muito bem treinados e altamente competentes que, por sua vez, terceirizam os diferentes estágios do processo produtivo a empresas especializadas em serviços agrários. Isso permite com que essas empresas corporativas empreguem as mais modernas técnicas agrícolas e alcancem aumentos substantivos no rendimento da safra, na flexibilidade para se adaptar a mudanças nas condições de mercado, e na produtividade global por meio de economias de escala. Este desenvolvimento tem resultado em lucros enormes para essas grandes empresas que, ao 
estender seu controle de forma gradual sobre outras partes da cadeia produtiva, tais como processamento e comercialização, expandem ainda mais seu poder de mercado.

Resumidamente, não é apenas o aumento na concentração fundiária, mas também e, sobretudo, a crescente concentração de capital em suas várias formas, que fortalece o poder do capital e enfraquece ainda mais o trabalho. Portanto, os altos níveis de desigualdade atuais se enraizarão e muito provavelmente se intensificarão.

\section{O Futuro do Campesinato e do Trabalho Rural}

Enquanto a questão agrária antes da virada neoliberal girava principalmente em torno dos problemas da distribuição fundiária, hoje outro aspecto-chave da questão agrária diz respeito ao trabalho. Esta problemática do trabalho nasce como consequência da questão agrária do capital, uma vez que a expansão e a intensificação das relações capitalistas transformou drasticamente o trabalho ${ }^{2} .1$ No final da década de 1970 e na década de 1980 , houve um importante debate em torno do destino do campesinato na América Latina, travado entre os 'campesinistas' (inspirados por Chayanov) e os 'descampesinistas' (inspirados por Marx e Lênin). Enquanto os primeiros defenderam que a agricultura familiar camponesa seguia viável e sobreviveria, os últimos enfatizaram os processos de diferenciação social e de proletarização dentre os camponeses (Kay, 2000).

Devido à emigração rural, menos de um quinto da população hodierna vive nas áreas rurais da América Latina. Embora não tenha desaparecido por inteiro, o campesinato passou por uma mudança substancial. Enquanto no passado a maior parte da renda do campesinato latino-americano fora obtido por meio da agricultura, estima-se que hoje esta fonte compõe menos da metade da mesma. A familia camponesa se sustenta, de forma crescente, por meio de atividades não agrícolas, especialmente por aquelas derivadas de trabalho assalariado fora do campo. A proporção do trabalho rural assalariado dentre a força de trabalho rural e camponesa tem aumentado de forma significativa. Com isso, os processos de proletarização do campesinato tem continuado rapidamente, uma vez que a grande parte dos minifúndios conseguem se sustentar hoje apenas por meio da renda salarial, remessas, pensões do estado e programas governamentais de combate à pobreza (Kay, 2006).

As interações entre o meio rural e o urbano multiplicaram-se e intensificaram-se ao ponto em que cerca de um quarto dos trabalhadores empregados no setor rural hoje vivem em áreas urbanas, uma vez que redes de transporte foram melhoradas, custos de viagens

\footnotetext{
${ }^{2}$ Para uma discussão extensa das várias dimensões da questão agrária, ver Akram-Lodhi e Kay (2009). 
reduzidos e o trabalho assalariado temporário multiplicado. Ademais, as condições de trabalho mudaram substancialmente. Enquanto o cultivo de soja é altamente mecanizado e requer pouco trabalho, o rápido crescimento das exportações de fruta, horticultura e flores vem providenciando oportunidades de emprego, especialmente para as mulheres nas estufas, nas plantas agro-processadoras e em outras partes da cadeia de produção. Ocorre-se, pois, uma feminização da agricultura (Deere, 2005).

Ao mesmo tempo, as condições de trabalho tornaram-se mais precárias em dois sentidos. Primeiramente, enquanto no passado o emprego costumava ser mais permanente, hoje é caracterizado por sua natureza temporária e flexível. Os fazendeiros capitalistas e as agroindústrias utilizam, crescentemente, o trabalho assalariado temporário para cumprir suas necessidades de trabalho, evitando fazer as contribuições para a seguridade social e outras responsabilidades para com seus trabalhadores. Torna-se, também, mais difícil para os trabalhadores se organizarem e pressionarem por direitos trabalhistas. Empregadores de trabalho temporário não costumam emitir contratos laborais nem respeitar legislação referente ao salário mínimo. Eles conseguem seguir com esses abusos com impunidade especialmente em áreas em que há uma abundância na oferta de trabalho, deixando os trabalhadores vulneráveis a condições de trabalho caracterizadas pela exploração. Observa-se uma preferência pela contratação de mulheres, motivada pela percepção de que seriam mais ágeis, menos conflituosas e, sobretudo, mais dispostas a aceitarem salários mais baixos. Outro motivo por trás da precarização das condições de trabalho está ligado à perspectiva subjetiva do trabalhador. A natureza repetitiva do trabalho e a maior intensidade e controle exercidos pelo empregador levam muitos a mudarem de emprego na esperança de encontrar melhores condições de trabalho. Com isso, a flexibilidade e mobilidade do trabalho se tornaram mais prevalecentes.

O campesinato, indubitavelmente, seguirá sobrevivendo, porém sob condições mais precárias. Não obstante, há algumas áreas em que gozam de perspectivas mais seguras, mesmo quando não melhores (Paz, 2006, p. 76). Estes nichos ou interstícios se encontram na agricultura ecológica e de trabalho intensivo ou aqueles em que a safra requer um monitoramento e cuidado constantes. Há, ainda, aquelas áreas onde os fazendeiros capitalistas não penetraram por que as dificuldades do terreno impedem a mecanização, o clima é demasiado desafiador, ou há uma falta de ligações de transporte e outros serviços. Este é o caso em certas terras altas ou em outras áreas remotas ou marginalizadas. Portanto, os fazendeiros capitalistas evitam, por ora, tais áreas. 


\section{Movimentos Camponeses e Indígenas e Assuntos Ambientais}

Os povos indígenas e os camponeses têm sido em muitas ocasiões as maiores e mais dinâmicas forças sociais a desafiar a transformação neoliberal na região. O Levante Zapatista em Chiapas, no México, e o Movimento dos Trabalhadores Rurais Sem Terra (MST), no Brasil, têm se mostrado as organizações mais emblemáticas e de maior visibilidade na luta contra o neoliberalismo global (Vergara-Camus, 2014). Em vários países, lograram alguns ganhos significativos, principalmente no que diz respeito a mudanças constitucionais, como por meio da declaração de um Estado e sociedade plurinacionais, consagrando seus direitos civis e culturais, assim como direitos territoriais e de autodeterminação (Assies, 2014). Movimentos indígenas no Equador e na Bolívia desempenharam papel relevante nas eleições para a presidência de Rafael Correa e de Evo Morales, respectivamente, que prometeram uma nova agenda de desenvolvimento pós-neoliberal embutida no slogan 'Bien Vivir' ou 'Vivir Bien' (Bretón, 2013). No Equador, organizações camponesas e indígenas, por meio do movimento camponês transnacional "La Vía Campesina" e várias ONGs, até conseguiram a aprovação de uma lei de "Soberania Alimentar" (sobre o qual trataremos mais adiante).

Muitas das promessas de uma grande reorientação na política agrária, ou mesmo de uma revolução agrária como na Bolívia, não se materializarem em larga escala ${ }^{3}$. Foi apresentada uma variedade de razões por trás de tal fracasso, tais como a falta de vontade política ou capacidade estatal, e a ausência de uma pressão de baixo pelos movimentos sociais devido a, por exemplo, a fragmentação do movimento indígena ou a sua cooptação. Em termos mais gerais, é matéria de debate o grau em que a "onda rosa" na América Latina trouxe de fato uma nova estratégia de desenvolvimento. A maioria dos casos, se não em todos, tem sido uma estratégia neo-desenvolvimentista ${ }^{4}$ que tem seguido com o processo econômico neo-extrativista (em grande medida na mineração, na agricultura e na pesca) e orientado à exportação, trazido pelos governos neoliberais anteriores, às vezes, paradoxalmente, com maior intensidade e sucesso (Veltmeyer e Petras, 2014). Até o momento, a "reorientação rosa" tem se dado principalmente na política social. Os programas sociais foram expandidos amplamente e levaram a uma grande redução na pobreza e melhorias significativas em saúde e educação. No entanto, foram financiados, em grande

\footnotetext{
${ }^{3}$ Embora haja alguns estudos que se esforçam por apresentar uma resposta a este enigma, estes ainda são parciais, limitados a um país particular, e ainda não apresentaram uma visão geral e análise comparativa sobre as várias experiências de esquerda. Para uma análises comparativa cf. Kay y Vergara-Camus (2018).

${ }^{4}$ Neodesenvolvimentismo na América Latina é influenciada pelo pensamento neoestruturalista da CEPAL, mas as estratégias neodesenvolvimentistas, até o momento, fracassaram na tentativa de trazer uma 'transformação produtiva com equidade', isto é, em que indústrias de alto valor agregado e a economia do conhecimento ganham proeminência, um fator-chave no neoestruturalismo (Gwynne \& Kay, 2004).
} 
medida, por meio da renda extraída pelo Estado das exportações de recursos naturais. Tais políticas sociais se demonstraram populares com o eleitorado e isto aponta para outro possível motivo pelo qual os governos relutam uma mudança radical no curso do neo-extrativismo.

Pesquisas sobre povos indígenas têm se ampliado nas últimas décadas, porém estes estudos, com frequência, desconsideram os processos de diferenciação socioeconômicos que vêm se desenvolvendo no interior deste grupo, além do fato de muitos povos não indígenas também serem pobres e explorados, embora enfrentando, provavelmente, menos discriminação (Bretón, 2008). Mais importante é o fato de que várias organizações camponesas, assim como a 'Via Campesina', concentram seus esforços organizacionais no setor da agricultura familiar, e, com isso, deixam de incorporar os trabalhadores assalariados rurais e a representação de seus interesses (Henderson, 2015). A consequência é o enfraquecimento dos movimentos camponeses e indígenas, tendo em vista o aumento dos trabalhadores sem terra e do precariado.

Quanto as questões ambientais, estas também passaram a ganhar destaque como consequência do impacto ecológico funesto de políticas neo-extrativistas, assim como por terem levado a conflitos com as comunidades indígenas e as populações locais. A enorme expansão do cultivo de soja está criando "desertos verdes" ao retirar sistemas tradicionais de rotação de cultura e espalhando a monocultura. Ainda, a soja geneticamente modificada e outras culturas transgênicas, como milho e algodão, vêm se espalhando com consequências nocivas ao meio ambiente e à saúde dos residentes locais por meio da expansão da 'dependência dos pesticidas'. A intensificação da presença carne ${ }^{5}$ nas dietas impulsiona a expansão pecuária, poluindo, assim, o meio ambiente e deteriorando os lençóis freáticos (a "pegada ecológica"). Embora uma demanda crescente por produtos ecológicos, entre alguns consumidores, e regulações governamentais mais restritivas podem levar algumas empresas do agronegócio a se redirecionarem parcialmente a práticas mais ecológicas e menos dependentes em hidrocarbonetos, estas permanecem uma contratendência minoritária. Apesar de medidas tomadas em prol da contenção do desmatamento no Amazonas, o mesmo continua, mesmo que em um passo mais lento. A mineração, a aquicultura, e plantações florestais estão esgotando e poluindo os recursos de água doce. Em suma, assuntos ambientais tornar-se-ão, indubitavelmente, ainda mais importante nos estudos agrários ao passo que mais terras são degradadas e a água se torna um recurso crescentemente escasso.

\footnotetext{
${ }^{5}$ No original em inglês lemos meatification, referente à dieta com grande presença da carne, sobretudo, bovina. Porém, por não possuirmos correlato em português traduzimos como "intensificação da presença da carne na dieta".
} 


\section{Abordagens Inovadoras?}

Os estudos da 'nova ruralidade' que emergiram na América Latina durante meados dos anos 1990 estavam dentre os primeiros a captar a mudança no caráter da economia e sociedade rurais da região após a virada neoliberal. Os autores principais foram, em sua maioria, sociólogos rurais latino-americanos, alguns dos quais influenciados por estudiosos europeus que escreveram sobre 'agricultura de tempo parcial', 'pluriatividade', e 'multifuncionalidade'. Surpreendentemente, a 'abordagem dos meios de vida', em grande parte britânica, com muitas semelhanças em relação à 'nova ruralidade', não é citada explicitamente por estes autores, e o inverso também é observado. Os 'novos ruralistas' não desenvolveram um quadro teórico coerente e várias linhas se distinguem entre si. Seu maior objetivo era chamar atenção para a situação adversa dos camponeses sob as pressões do neoliberalismo global e encorajar os governos, ONGs, políticos e instituições internacionais a implementarem programas de desenvolvimento rural focados na pobreza rural, nas comunidades indígenas e nas mulheres (Kay, 2008).

Mesmo considerando útil a análise dos novos ruralistas, a mesma se depara com limitações, particularmente para a compreensão de forças globais, de padrões de acumulação capitalista, e de configurações políticas e de classe que moldam a mudança agrária. Essas limitações não foram superadas pela bastante popular abordagem territorial, que busca maneiras de articular pequenos proprietários com as cadeias mais dinâmicas de valor ou de matérias-primas como um modo de impulsionar a agricultura camponesa. Embora a abordagem territorial se demonstra útil para planos regionais, sua meta de estender os benefícios do crescimento de forma mais abrangente desmoronam em grande medida dados os conflitos políticos, étnicos e de classe existentes.

Devido à limitação das abordagens acima discutidas, assim como outras, para os estudos agrários, tenho trazido para os meus escritos uma abordagem inspirada no Marxismo, embora de maneira parcial e muitas vezes eclética. O método histórico-materialista e seus conceitos, tais como conflito e formação de classe, diferenciação social e econômica, consciência social e política, processos de acumulação de capital, formas de transição entre diferentes formações socioeconômicas, criação e apropriação de mais-valia, processos de exploração e dominação, trazem um enfoque mais afiado para as principais contradições e problemas enfrentados pela economia e sociedade rurais.

$\mathrm{Na}$ minha perspectiva, a abordagem histórica-mundial do materialismo histórico é particularmente relevante para a compreensão dos processos contemporâneos da globalização 
e de seus problemas. Escusado será dizer que qualquer abordagem utilizada não prescinde de sustentação empírica. Não é o caso que o materialismo histórico apresente a capacidade de explicar tudo. Para a compreensão de certos problemas, podem-se requerer outras abordagens, tais como as inovadoras perspectivas feministas, ecológicas e pós-coloniais. Portanto, é necessário manter uma mente aberta, e algo de ecletismo auxilia no ganho de uma visão mais abrangente e uma percepção mais profunda sobre os problemas que desejamos analisar.

\section{Conclusões: temas contínuos e emergentes}

Destaquei a crescente proeminência da questão agrária do capital devido ao imenso poder que o capital adquiriu neste período da globalização neoliberal. Empresas do agronegócio, supermercados, capital financeiro e conglomerados "translatinos" continuarão a estender sua dominação sobre a paisagem rural latino-americana e além. Este é o futuro provável, ao menos que haja um contra-movimento poderoso contra o neoliberalismo global, cujo sucesso depende da formação de alianças entre movimentos transnacionais de camponeses, de indígenas e de trabalhadores rurais, organizações políticas anti-neoliberais e movimentos ambientais globais. Desse modo, a questão social e política de como desenvolver um contra-movimento de tal magnitude, assim como definir os principais objetivos desse programa alternativo requerem mais pesquisa.

A questão agrária do trabalho é também fundamental dada sua relação dialética e conflitiva com o capital. Embora dever-se-ia seguir confrontando os problemas de pequenos agricultores, os trabalhadores assalariados rurais são, atualmente, predominantes. Os problemas da pequena agricultura e do trabalho assalariado rural estão ligados; os trabalhadores assalariados rurais trazem, no entanto, particularidades que ainda não foram inteiramente discutidas. Estes são expostos a situações de emprego abusivas e precárias e lhes faltam, com frequência, organizações sociais que defendam seus interesses. À vista disso, são necessárias maiores pesquisas que apontem caminhos para desenvolver sua capacidade organizativa e para buscar o seu empoderamento para que exerçam pressão sobre empregadores e governos em prol de assegurar condições de trabalho.

Os assuntos agrários se desvaneceram com o deslumbramento do período da reforma agrária, porém ganharam nova proeminência com a emergência do movimento indígena, a crise alimentar (2007-2008), os conflitos gerados pelo novo agro-extrativismo, e a mobilização da Via Campesina (VC) e outros movimentos sociais contrários à apropriação de terras e ao livre comércio, e a favor de uma reforma agrária de baixo para cima e da 
'soberania alimentar' (McMichael, 2008; Gascón \& Montagut, 2010; Martínes-Torres \& Rosset, 2010). A VC é contrária à agricultura industrializada corporativa e seu crescente controle sobre os recursos naturais e a tecnologia. Em lugar disso, propõe um novo regime alimentar baseado na 'soberania alimentar' que se enquadra dentro do discurso dos direitos humanos. Traz uma preocupação em torno dos direitos a alimento, justiça, democratização e o desenvolvimento rural baseado em direitos que promove a pequena agricultura sustentável e agro-ecológica, mercados locais ou 'aninhados', cooperação e solidariedade (McMichael, 2009, p. 294). Emerge-se como alternativa ao neoliberalismo, que vem inspirando e mobilizando muitos, desde ativistas, intelectuais e movimentos sociais. A "soberania alimentar" da VC vem sendo contestada, gerando muito debate, e continuará, indubitavelmente, a evoluir (McKay et al., 2014; Bernstein, 2014; Jansen, 2015).

A questão agrária hodierna precisa ser posta para além do estado-nação para que possa contestar o atual regime alimentar corporativo, neoliberal e global (Borras et al., 2009), embora o estado-nação permanece o espaço mais viável, no imediato, de contestação. Como realizar um regime alimentar mais justo e sustentável é o principal desafio adiante de pesquisadores e ativistas dentro e fora da América Latina.

\section{Referências Bibliográficas}

AKRAM-LODHI, A. H., \& KAY, C. (Eds.). Peasants and globalization: Political economy, rural transformation and the agrarian question. London: Routledge, 2009.

ALMEYRA, G; CONCHEIRO BÓRQUEZ, L; MENDES PEREIRA, J. M., PORTOGONÇALVES, C. W. (Eds.). Capitalismo: Tierra y poder en América Latina (1982-2012), 3 volumenes. México, D.F. \& Buenos Aires: Universidad Autónoma Metropolitana, Ediciones Continente \& CLACSO, 2014.

ASSIES, W.. "Self-determination and the 'new partnership': the politics of indigenous peoples and states" In: T. SALMAN, S. MARTÍ I PUIG, G. VAN DER HAAR (Eds.), Dignity for the voiceless: Willem Assies's anthropological work in context (pp. 154-185). Oxford: Berghahn Books, 2014.

BERNSTEIN, H.. "Food sovereignty via the 'peasant way': a sceptical view". The Journal of Peasant Studies 41(6): 1031-1063, 2014.

BORRAS Jr., S. M., EDELMAN, M., \& KAY, C. (Eds.). Transnational agrarian movements confronting globalization. Oxford: Blackwell-Wiley, 2009. 
BORRAS Jr., S. M., KAY, C.; GÓMEZ, S., \& WILKINSON. J. (Eds.). Land grabbing and global capitalist accumulation: Key features in Latin America. special issue of the Canadian Journal of Development Studies 33(4): 399-551, 2012.

BRETÓN SOLO DE ZALDÍVAR, V.. "From agrarian reform to ethnodevelopment in the highlands of Ecuador”. Journal of Agrarian Change 8(4): 583-617, 2008.

. "Etnicidad, desarrollo y 'buen vivir': reflexiones críticas en perspectiva histórica”. European Review of Latin American and Caribbean Studies 95: 71-95, 2013.

DEERE, C. D.. "The feminization of agriculture? Economic restructuring". Rural Latin America. Occasional Paper 1. Geneva: UNRISD, 2005.

GASCÓN, J., \& MANTAGUT, X. (Eds.). Estado, movimientos sociales y soberanía alimentaria en América Latina: ¿Hacia un cambio de paradigma agrario?. Quito: FLACSO, 2010.

GWYNNE, R. N., \& KAY, C.. The alternatives to neoliberalism. In R. N. Gwynne \& C. Kay (Eds.). Latin America transformed: Globalization and modernity (pp. 253-267). Hodder: London, 2004.

HENDERSON, T. P.. Food sovereignty and the Via Campesina in Mexico and Ecuador: Class dynamics, struggles for autonomy and the politics of resistance. Unpublished $\mathrm{PhD}$ thesis, SOAS, University of London, 2015.

JANSEN, K.. "The debate on food sovereignty theory: Agrarian capitalism, dispossession and agroecology". The Journal of Peasant Studies 42(1): 213-232, 2014.

KAY, C.. “¿El fin de la reforma agraria en América Latina? El legado de la reforma agraria y el asunto no resuelto de la tierra". Revista Mexicana de Sociología 60(4): 61-98, 1998.

KAY, C.. "Latin America's agrarian transformation: Peasantization and proletarianization". In: D. BRYCESON, C. KAY \& J. MOOIJ (Eds.), Disappearing peasantries? Rural labour in Africa, Asia and Latin America (pp. 123-138). Bourton-on-Dunsmore: ITDG-Practical Action Publishing, 2000.

. "Rural poverty and development strategies in Latin America". Journal of Agrarian Change 6(1): 455-508, 2006.

. "Reflections on Latin American rural studies in the neoliberal globalization period: A new rurality?". Development and Change 39(6): 915-943, 2008

• "Visión de la concentración de la tierra en América Latina". In: A. BERRY, C. KAY, L. Martínez Valle \& L. North, La Concentración de la tierra: Un problema prioritario en el Ecuador contemporáneo (pp. 15-42). Quito: Ediciones Abya-Yala, 2014. 
KAY, C. \& VERGARA-CAMUS, L. (Eds.), La cuestión agraria y los gobiernos de izquierda en América Latina: campesinos, agronegocio y neodesarrollismo. Buenos Aires: CLACSO, 2018.

MARTÍNEZ-TORRES, M. E., \& ROSSET, P. M.. "La Vía Campesina: The birth and evolution of a transnational social movement". The Journal of Peasant Studies 37(1): 149$175,2010$.

MCKAY, B., NEHRING, R., \& WALSH-DILLEY, M.. "The 'state' of food sovereignty in Latin America". The Journal of Peasant Studies 41(6): 1175-2000, 2014.

MCMICHAEL, P.. "Peasants make their own history, but not just as they please". In: S. M. BORRAS, Jr., M. EDELMAN \& C. KAY (Eds.). Transnational agrarian movements confronting globalization (pp. 37-60). Oxford: Blackwell-Wiley, 2010.

. "Food sovereignty, social reproduction and the agrarian question". In: A. H. AKRAM-LODHI \& C. KAY (Eds.). Peasants and globalization: Political economy, rural transformation and the agrarian question (pp. 288-312). London: Routledge, 2009.

PAZ, R.. "El campesinado en el agro argentino: ¿Repensando el debate teórico o un intento de reconceptualización?”. European Review of Latin American and Caribbean Studies, 81: 65$85,2006$.

VELTMEYER, H., \& PETRAS, J.. The New Extractivism: A post-neoliberal development model or imperialism of the twenty-first century? London: Zed Books, 2014.

VERGARA-CAMUS, L.. Land and freedom: The MST, the Zapatistas and peasant alternatives to neoliberalism. London: Zed Books, 2014.

\section{A questão agrária e a transformação rural neoliberal na América Latina}

\section{Resumo}

Desde a virada neoliberal na América Latina, a economia e sociedade rural vêm experimentando uma grande transformação. O capital corporativo e as agroindústrias transnacionais se apoderaram da agricultura transformando radicalmente as relações econômicas e sociais da produção que levam à precarização e feminização da mão de obra rural, assim como à intensificação do trabalho. Os camponeses enfrentam condições cada vez mais difíceis, tendo que buscar com maior frequência renda fora da agricultura, principalmente por meio de atividades salariais precárias, com o fim de ganhar a vida, impulsionando, assim, o processo de proletarização. Os focos da 'nova ruralidade' e 'territoriais' trataram de explicar estas transformações, no entanto apresentam limitações. Por outro lado, uma visão desde a economia política sobre a questão agrária se considera mais promissora. Movimentos que contestam o neoliberalismo surgiram, encabeçados pelos povos indígenas e a população rural pobre, às vezes vinculados ao movimento camponês transnacional 'Via Campesina'. Seu principal objetivo é a construção de um sistema agrário alternativo baseado na 'soberania alimentar', que é promissor, embora também polêmico.

Palavras-chave: mudança agrária, neoliberalismo, concentração da terra e do capital, precarização do trabalho, América Latina.

\section{La Cuestión Agraria y la Transformación Rural Neoliberal en Latinoamérica}




\title{
Resumen
}

Desde el giro neoliberal en América Latina la economía y sociedad rural han experimentado una gran transformación. El capital corporativo y las agroindustrias transnacionales se han apoderado de la agricultura transformando radicalmente las relaciones económicas y sociales de producción que llevan a la precarización y feminización de la mano de obra rural, así como a la intensificación del trabajo. Los campesinos enfrentan condiciones cada vez más difíciles teniendo que buscar con mayor frecuencia ingresos fuera de la finca, principalmente a través de actividades salariales precarias, con el fin de ganarse la vida impulsando con ello el proceso de proletarización. Los enfoques de la 'nueva ruralidad' y 'territoriales' trataron de explicar estas transformaciones pero tienen limitaciones. En cambio, una visión desde la economía política sobre la cuestión agraria se estima más prometedora. Movimientos contestatarios del neoliberalismo han surgido encabezado por los pueblos indígenas y la

población rural pobre, a veces vinculado al movimiento campesino transnacional 'Vía Campesina'. Su principal objetivo es la construcción de un sistema agrario alternativo basado em la 'soberanía alimentaria', que es prometedor, pero también polémico.

Palabras clave: cambio agrario, neoliberalismo, concentración de la tierra y el capital, precarización del trabajo, América Latina.

\section{The Agrarian Question and the Neoliberal Rural Transformation in Latin America}

\begin{abstract}
Since the neoliberal turn in Latin America the rural economy and society has experienced a great transformation. Corporate capital and transnational agro-industries have taken hold of agriculture radically transforming the economic and social relations of production leading to the precarization and feminisation of rural labour as well as the intensification of work. Peasant farmers were further squeezed having to increasingly find off-farm incomes, largely through precarious wage labour activities, so as to make a living thereby furthering the process of proletarianization. The 'new rurality' and 'territorial' approaches tried to take account of these transformations but they are found wanting. Instead, a political economy view to the agrarian question is found more promising. A counter-movement to neoliberalism has emerged spearheaded by indigenous peoples and the rural poor, sometimes linked to the transnational peasant movement 'Via Campesina'. Their main aim is to construct an alternative agrarian system based on 'food sovereignty' which is promising but also controversial.
\end{abstract}

Keywords: agrarian change, neoliberalism, land and capital concentration, labour precarization, Latin America. 